\title{
Primary adult heart tumor
}

INSERM

\section{Source}

INSERM. (1999). Orphanet: an online rare disease and orphan drug data base. Primary adult heart tumor. ORPHA:874

A rare disorder that manifest in adults and generally present with a variety of non-specific manifestations (depending on tumor site and infiltration) such as weight loss, exhaustion, hemorrhagic pericardial effusion, heart failure, arrhythmias, and embolisms, or that can also be asymptomatic. In adults $75 \%$ of heart tumors are benign, with myxoma being the most common benign tumor (accounting for $50-70 \%$ of all primary heart tumors) and rhabdomyosarcoma (see this term) comprising $75 \%$ of malignant heart tumors. Other malignant tumors of the heart include fibrosarcoma and leiomyosarcoma (see these terms). 